\title{
Impact of Time Delay on Short Term Outcome of Primary Percutaneous Coronary Intervention (PCI) in Bangladeshi Population
}

\author{
MD GOLAM MORSHED ${ }^{1}$, M G AZAM ${ }^{1}$, MD MINHAJ AREFIN ${ }^{1}$, KHONDKER SHAHEED HUSSAIN ${ }^{1}$, \\ JAFRIN JAHAN ${ }^{1}$, NISHAT AHMED, MD. MUKHLESUR RAHMAN ${ }^{2}$ \\ ${ }^{1}$ Department of Cardiology, National Institute of Cardiovascular Diseases (NICVD), Dhaka, Department of Cardiology, \\ ${ }^{2}$ Bangabandhu Sheikh Mujib Medical University (BSMMU), Dhaka
}

Address of Correspondence: Dr M G Azam, Professor, Department of Cardiology, NICVD, Dhaka, Bangladesh. Email:mgazam71@yahoo.com

\begin{abstract}
:
Background: Now-a-days primary percutaneous coronary intervention (pPCI) is being increasingly done in our country as the treatment of acute ST elevation myocardial infarction (STEMI). Time until treatment is paramount in the management of STEMI. But the time delay to pPCI how much influencing the outcome in our setting is mostly unknown.So we evaluated the influence of total ischemic time on myocardial reperfusion and short term clinical outcome in patients with STEMI treated with primary PCI.

Materials and methods: This prospective observational study was conducted from August 2016 to March 2017in the Department of Cardiology, National Institute of Cardiovascular Diseases (NICVD), Dhaka. Forty eight (48) acute STEMI patients were selected by purposive sampling based on inclusion and exclusion criteria dividing into two groups as early treatment group (group- $A$ ) in whom pain to pPCI time was $<6$ hours and late treatment group (group-B) in whom pain to pPCI time was 6-12 hours. Angiographic (TIMI flow grade 3 \& $M B G$ 3) \& short term clinical outcome (MACE, heart failure, major bleeding, minor bleeding, cardiogenic shock, significant arrhythmia, instent thrombosis) were observed and compared between these two groups.

Results:The relationship between total ischemic time and 30-day mortality \& morbidity were assessed and compared with early and late pPCI group. The overall 30-day mortality rate was $4.2 \%$, heart failure was $6.2 \%$, cardiogenic shock was $4.2 \%$, major bleeding was $2.1 \%$ and minor bleeding was $14.6 \%$. Mortality and morbidity were higher in longer ischemic time group than shorter ischemic time group. In multivariate regression analysis, the factors independently influencing the adverse short term outcome were advance age (OR 1.51, 95\% CI 1.105 to 4.101, $p=0.03)$, hypertension (OR 2.44, 95\% CI 1.102 to 4.281, $p=0.02)$, diabetes mellitus (OR 2.51, 95\% CI 1.200 to 4.987, p=0.02), anterior MI (OR 1.38, 95\% CI 1.001 to 2.872, $p=0.03)$, multivessel disease (OR 2.35, 95\% CI 1.010 to 5.371, p=0.02), pain to door time (OR 1.66, CI 1.099 to $2.2 .722, p=0.04)$, and total ischemic time (OR 2.67, 95\% CI 1.122 to $5.784, p=0.02)$. Even after correction for predictive baseline and procedural variables of the univariate analysis, longer total ischemic time was the most significant independent predictor $(O R 2.67, p=0.02)$ of short term adverse outcome of primary PCI. The current status of time delay in our country revealed symptom onset to door time was $5.6 \pm 2.4$ hours, door to balloon time was $1.9 \pm 1.1$ hours and total ischemic time was $7.3 \pm 2.6$ hours.

Conclusion: According to this study finding, there is prognostic implication of time delay in patients with STEMI undergoing primary PCI. Therefore, all efforts should be made to shorten total ischemic time, including reduction in patient related delays, to improve clinical outcome of STEMI patients.
\end{abstract}

Key Words:Primary PCI (pPCI), ST elevation MI (STEMI).

University Heart Journal 2018; 14(2): 77-82

\section{Background:}

Coronary artery disease (CAD) is the most common form of heart disease and single most important cause of premature death in most part of the world. By the year 2020 it will become the major cause of death in all the region of the world. ${ }^{1}$ Acute myocardial infarction (AMI) is one of the leading causes of death and disability. It generally occurs due to sudden occlusion of a coronary artery by formation of thrombus at the site of fissured or ruptured atherosclerotic plaque. ${ }^{2}$ The resultant thrombus that is formed interrupts blood flow and leads to an imbalance between oxygen supply and demand, if this imbalance is severe and persistent, it leads to myocardial necrosis. ${ }^{3}$ 


\section{Materials and methods:}

This was a prospective observational study and was done in department of cardiology in

National Institute of Cardiovascular Diseases (NICVD), Dhaka, Bangladesh from August 2016 to March 2017. Patients presented with acute STEMI admitted in CCU in National Institute of Cardiovascular Diseases who full filled inclusion and exclusion criteria were my study population. Sampling was purposive. Considering nonresponse, unavailability of some respondent, inflation in the desired sample size is planned.Targeted sample size for the study $=40+8=48$.

Study subjects were divided into two groups on the basis of time delay to reperfusion:

Group A: Patients whose symptom onset to first balloon/ stent time was $<6$ hours were included in this group

Group B: Patients whose symptom onset to first balloon/ stent time was 6-12 hours were included in this group

\section{Selection criteria}

\section{Inclusion criteria:}

- Patients presented within 12 hours of onset of typical chest pain with ST segment elevation in ECG and diagnosed as a case of acute STEMI (ST segment elevation myocardial Infarction).

\section{Exclusion criteria:}

Patients having LBBB (left bundle branch block). Patients with history of old myocardial infarction. Patients who received thrombolytic therapy. Patients with high bleeding risk. Patients with valvular heart disease. Patients with cardiomyopathies Patients with established renal failure (S. Creatinine $>2 \mathrm{mg} / \mathrm{dl}$.). Patients with stroke. Patients with malignancy

\section{Methods of statistical analysis:}

All variables were entered into the Statistical Package for Social Sciences, version 16 (SPSS Inc., Chicago, Illinois).Data was presented as frequency and percents for categorical variables and as mean with standard deviation for quantitative variables. Paired t-test was done for quantitative variables where applicable. Univariate and multivariate regression analysis were done with variables may be related to adverse outcome with calculated risk ratios \& odds ratios [OR] for independent variables with $95 \%$ confidence intervals $[\mathrm{CI}]$. $\mathrm{P}$ value $<0.05$ were considered as significant.

\section{Results and observations:}

This prospective observational study was conducted in the National Institute of Cardiovascular Diseases (NICVD), Dhaka during the period of August 2016 to March 2017. The main objective of this study was to assess the impact of time delay on short term outcome of primary Percutaneous Coronary Intervention (PCI) among a case series of Bangladeshi population presented with acute ST elevation myocardial infarction (STEMI).

A total of 48 patients with acute ST elevation myocardial infarction who were consented to PCI were included in this study. Patients were classified as early treatment group (group-A) in whom treatment delay was $<6$ hours and late treatment group (group-B) in whom treatment delay was 6-12 hours. Two patients died at the same day of the procedure and all other patients were followed up in hospital and for one month.

Group A: Total ischemic time $<6$ hrs. Group B: Total ischemic time $6-12 \mathrm{hrs}$. Quantitative data expresses in mean $\pm \mathrm{SD}$ and qualitative data expresses in no. \& $(\%)$. $\mathrm{s}=$ Significant $(\mathrm{p}<0.05), \mathrm{ns}=$ Not significant $(\mathrm{p}>0.05) \mathrm{p}$ value reached from Chi Square test

Table-I

Comparison of risk factors between early treatment group and late treatment group $(n=48)$

\begin{tabular}{lcccc}
\hline Variables & $($ Group A) $\mathrm{n}=23$ & (Group B) $\mathrm{n}=25$ & Total $(\mathrm{n}=48)$ & $\mathrm{p}$ value \\
\hline Age in years & $51.5 \pm 11.1$ & $59.8 \pm 14.7$ & $55.9 \pm 13.6$ & $0.03^{\mathrm{s}}$ \\
Hypertension & $6(26.1 \%)$ & $14(56.0 \%)$ & $20(41.7 \%)$ & $0.03^{\mathrm{s}}$ \\
Diabetes mellitus & $7(30.4 \%)$ & $15(60.0 \%)$ & $22(45.8 \%)$ & $0.04^{\mathrm{s}}$ \\
Dyslipidemia & $11(47.8 \%)$ & $17(68.0 \%)$ & $28(58.3 \%)$ & $0.17^{\text {ns }}$ \\
Smoker & $15(65.2 \%)$ & $20(80.0 \%)$ & $35(72.9 \%)$ & $0.25^{\text {ns }}$ \\
\hline
\end{tabular}

Group A: Total ischemic time $<6 \mathrm{hrs}$. Group B: Total ischemic time $6-12 \mathrm{hrs}$. Quantitative data expresses in mean $\pm \mathrm{SD}$ and qualitative data expresses in no. \& $(\%) . s=$ Significant $(\mathrm{p}<0.05), \mathrm{ns}=$ Not significant $(\mathrm{p}>0.05) \mathrm{p}$ value reached from Chi Square test 
The above table depicts the comparison of risk factors between early treatment group and late treatment group among the study population. Age, hypertension and diabetes were higher in patients with longer symptom onset to balloon time than in those with shorter symptom onset to balloon time and there were statistical significant association ( $p=0.03, p=0.03, p=0.04)$ respectively. Among the study population overall $41.7 \%$ were hypertensive, $45.8 \%$ were diabetic, 58.3\% were dyslipidaemic and $72.9 \%$ were smoker.

Figure: Bar diagram showing site of myocardial infarction between group A (early treatment group) and group B (late treatment group)

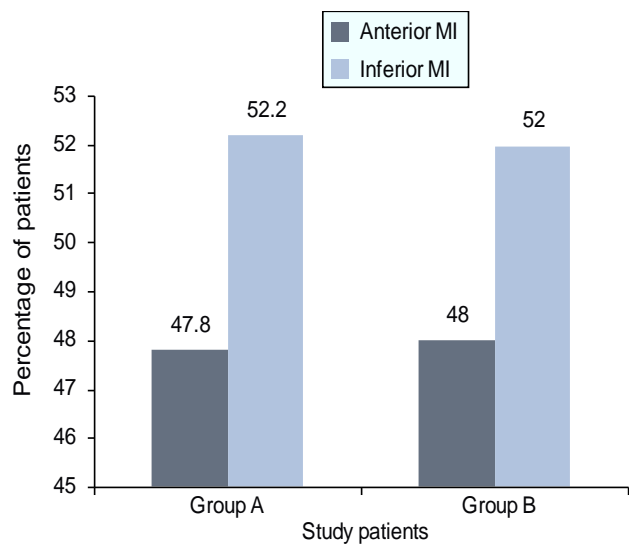

Group A: Total ischemic time $<6$ hrs.. Group B: Total ischemic time $6-12 \mathrm{hrs}$.

Table-II

Comparison of LVEF (\%) between two groups before pPCI $(n=48)$

\begin{tabular}{lcccccccc}
\hline LVEF (\%) & \multicolumn{2}{c}{ Group A $(\mathrm{n}=23)$} & & \multicolumn{2}{c}{ Group B $(\mathrm{n}=25)$} & & \multicolumn{2}{c}{ Total $(\mathrm{n}=48)$} \\
\cline { 2 - 3 } & Number & $\%$ & & Number & $\%$ & & Number & $\%$ \\
\hline dd 35 (Severe)36 - 44 (Moderate) & 0 & 0.0 & & 0 & 0.0 & & 0 & 0.0 \\
& 2 & 8.7 & & 7 & 28.0 & & 9 & 18.8 \\
45 -54 (Mild) & 20 & 87.0 & & 17 & 68.0 & & 37 & 77.1 \\
$\geq 55$ (Normal) & 1 & 4.3 & & 1 & 4.0 & & 2 & 4.2 \\
\hline
\end{tabular}

Group A: Total ischemic time $<6$ hrs.

Group B: Total ischemic time $6-12$ hrs.

$\mathrm{s}=$ Significant $(\mathrm{p}<0.05)$,

$\mathrm{p}$ value reached from unpaired t-test.

Table-III

Comparison of LVEF (\%) between two groups after pPCI ( $n=48)$

\begin{tabular}{|c|c|c|c|c|c|c|c|}
\hline \multirow[t]{2}{*}{$\overline{\operatorname{LVEF}(\%)}$} & \multicolumn{2}{|c|}{ Group A $(n=23)$} & \multicolumn{2}{|c|}{ Group B $(n=25)$} & \multicolumn{2}{|c|}{ Total $(n=48)$} & \multirow[t]{2}{*}{$P$ value } \\
\hline & Number & $\%$ & Number & $\%$ & Number & $\%$ & \\
\hline dd 35 (Severe) & 0 & 0.0 & 0 & 0.0 & 0 & 0.0 & \\
\hline $36-44$ (Moderate) & 0 & 0.0 & 0 & 0.0 & 0 & 0.0 & \\
\hline $45-54$ (Mild) & 2 & 8.7 & 3 & 12.0 & 5 & 10.4 & \\
\hline$\geq 55$ (Normal) & 21 & 91.3 & 22 & 88.0 & 43 & 89.6 & \\
\hline
\end{tabular}

Group A: Total ischemic time $<6$ hrs. Group B: Total ischemic time $6-12$ hrs.s = Significant $(\mathrm{p}<0.05)$,

$\mathrm{p}$ value reached from unpaired t-test.

Table-IV

Adverse outcomes between group A (early treatment group) and group B (late treatment group) at one month.

\begin{tabular}{|c|c|c|c|c|c|c|c|}
\hline \multirow[t]{2}{*}{ Adverse outcome } & \multicolumn{2}{|c|}{ Group A $(n=23)$} & \multicolumn{2}{|c|}{ Group B $(n=25)$} & \multicolumn{2}{|c|}{ Total $(n=48)$} & \multirow[t]{2}{*}{$\mathrm{p}$ value } \\
\hline & No. & $(\%)$ & No. & $\%$ & No. & $\%$ & \\
\hline Death & 0 & 0.0 & 2 & 8.0 & 2 & 4.2 & $0.49^{\mathrm{ns}}$ \\
\hline Heart failure & 0 & 0.0 & 3 & 12.0 & 3 & 6.2 & $0.24^{\mathrm{ns}}$ \\
\hline Cardiogenic shock & 0 & 0.0 & 2 & 8.0 & 2 & 4.2 & $0.49^{\mathrm{ns}}$ \\
\hline Major bleeding & 0 & 0.0 & 1 & 4.0 & 1 & 2.1 & $0.69^{\text {ns }}$ \\
\hline Minor bleeding & 1 & 4.3 & 6 & 24.0 & 7 & 14.6 & $0.04^{\mathrm{s}}$ \\
\hline
\end{tabular}

Group A: Total ischemic time $<6$ hrs. Group B: Total ischemic time $6-12$ hrs. $S=$ Significant $(p<0.05)$, ns $=$ Not significant $(p>0.05)$. $p$ value reached from Fisher's Exact test 
Table-V

Univariate logistic regression of adverse short term outcome of pPCI.

\begin{tabular}{lccccc}
\hline Variables of interest & & S.E. & p value & OR & $95 \%$ CI \\
\hline Advance age ( $>60$ years $)$ & 0.368 & 0.431 & $0.02^{\mathrm{s}}$ & 1.82 & $1.143-4.219$ \\
Male gender & 0.152 & 0.101 & $0.30^{\text {ns }}$ & 1.24 & $0.057-1.541$ \\
Hypertension & 0.589 & 0.379 & $0.01^{\mathrm{s}}$ & 2.66 & $1.110-5.581$ \\
Diabetes mellitus & 0.470 & 0.465 & $0.01^{\mathrm{s}}$ & 2.78 & $1.110-3.811$ \\
Smoker & 0.678 & 0.473 & $0.33^{\text {ns }}$ & 0.78 & $0.120-2.111$ \\
Anterior MI & 0.439 & 0.351 & $0.02^{\mathrm{s}}$ & 1.54 & $1.110-3.245$ \\
Multi vessel disease & 0.578 & 0.354 & $0.01^{\mathrm{s}}$ & 2.55 & $1.220-6.37$ \\
Lower LVEF $(<45 \%)$ & 0.248 & 0.176 & $0.12^{\mathrm{ns}}$ & 1.99 & $0.494-2.872$ \\
Pain to door time & 0.420 & 0.378 & $0.03^{\mathrm{s}}$ & 1.92 & $1.071-2.824$ \\
Door to balloon time & 0.119 & 0.101 & $0.31^{\mathrm{ns}}$ & 0.99 & $0.110-1.780$ \\
Longer total ischemic time $(6-12 \mathrm{hrs})$ & 0.591 & 0.312 & $0.01^{\mathrm{s}}$ & 2.97 & $1.154-7.889$ \\
\hline
\end{tabular}

Dependent variable: Adverse in-hospital outcome

Independent variables: Advance age, male gender, hypertension, diabetes mellitus, smoking, anterior MI, multi vessel disease, lower LVEF (<45\%), pain to door time, door to balloon time and longer total ischemic time (6-12 hrs).

$\mathrm{s}=$ Significant $(\mathrm{p}<0.05), \mathrm{ns}=$ Not significant $(\mathrm{p}>0.05)$

Univariate logistic regression analysis

Table-VI

Multivariate logistic regression of adverse short term outcome of pPCI.

\begin{tabular}{lccccc}
\hline Variables of interest & & S.E. & p value & OR & $95 \%$ CI \\
\hline Advance age $(>60 \mathrm{yrs})$ & 0.302 & 0.290 & $0.03^{\mathrm{s}}$ & 1.51 & $1.105-4.101$ \\
Male gender & 0.141 & 0.101 & $0.45^{\mathrm{ns}}$ & 1.11 & $0.017-1.541$ \\
Hypertension & 0.479 & 0.361 & $0.02^{\mathrm{s}}$ & 2.44 & $1.102-4.281$ \\
Diabetes mellitus & 0.435 & 0.304 & $0.02^{\mathrm{s}}$ & 2.51 & $1.200-4.987$ \\
Smoker & 0.220 & 0.119 & $040^{\mathrm{ns}}$ & 0.88 & $0.111-2.509$ \\
Anterior MI & 0.339 & 0.279 & $0.03^{\mathrm{s}}$ & 1.38 & $1.001-2.872$ \\
Multi vessel disease & 0.478 & 0.342 & $0.02^{\mathrm{s}}$ & 2.35 & $1.010-5.371$ \\
Lower LVEF(<45 \%) & 0.232 & 0.107 & $0.27^{\mathrm{ns}}$ & 1.44 & $0.549-1.770$ \\
Pain to door time & 0.410 & 0.301 & $0.04^{\mathrm{s}}$ & 1.66 & $1.099-2.722$ \\
Door to balloon time & 0.110 & 0.101 & $0.4^{\mathrm{ns}}$ & 0.88 & $0.120-1.699$ \\
Longer total ischemic time(6-12 hrs) & 0.569 & 0.300 & $0.02^{\mathrm{s}}$ & 2.67 & $1.122-5.784$ \\
\hline
\end{tabular}

This figure shows that patients with early treatment group had $52.2 \%$ inferior MI and $47.8 \%$ had anterior MI and patients with late treatment group $52 \%$ had inferior MI and $48 \%$ had anterior MI. Overall inferior MI (52\%) was more than anterior MI (48\%).

The above table displays that among early presenters (group A) $8.7 \%$ had moderate LV dysfunction and $87 \%$ had mild LV dysfunction but among late presenters (group B) $28 \%$ had moderate LV dysfunction and $68 \%$ had mild LV dysfunction before pPCI.

The above table displays that after pPCI 91.3\% patients had good LV function among those who are early presenter having total ischemic time $<6$ hours and those who are late presenter having longer total ischemic time
(6-12 hours) among them $88 \%$ had good LV function.

The above table depicts that mortality in 1 month was $4.2 \%$, heart failure was $6.2 \%$, cardiogenic shock was $4.2 \%$, major bleeding was $2.1 \%$ and minor bleeding was $14.6 \%$. Most of the adverse outcomes occurred in late treatment group (6-12 hours from symptom onset to primary PCI) within one month. So it can be concluded that delay in symptom onset to balloon time (6-12 hrs) adversely affects the prognosis in patients with STEMI.

Above table demonstrates the binary logistic regression analysis of odds ratio (OR) for characteristics of the subjects likely to develop adverse short time outcome of primary PCI. The variables revealed to be significantly associated with univariate analysis were entered into the 
model directly. In regression analysis advance age, hypertension, diabetes mellitus, anterior MI, multi vessel disease, pain to door time and longer total ischemic time (6-12hrs) were found to be the significant predictors for developing adverse short term outcome of primary PCI.

\section{Multivariate logistic regression analysis}

Above table demonstrates the binary logistic regression analysis of odds ratio (OR) for characteristics of the subjects likely to develop adverse short time outcome of primary PCI. The variables revealed to be significantly associated with multivariate analysis were entered into the model directly. In regression analysis advance age, hypertension, diabetes mellitus, anterior MI, multi vessel disease, pain to door time and longer total ischemic time (6-12hrs) were found to be the independent predictors for developing adverse short term outcome of primary PCI with ORs being 1.51, 2.44, 2.51, 1.38, 2.35, 1.66 and 2.67 respectively.

In multivariate analysis, weadjusted for potential confounders associated with the endpoints in univariate analysis.After correction for predictive baseline and procedural variables of the univariate analysis, longer total ischemic time was found as the most significant independent predictor (OR 2.67, $\mathrm{p}=0.02$ ) of short term adverse outcome of primary PCI.

Limitation of the study:

Although the result of this study supports the research question, there were some limitations of this study. These are:

- As the sample size was small, it was difficult to generalize the findings to the 02220reference population.

- Non randomized sampling done.

- Single centered study which didn't represent the status of the whole country.

- Short term observation.

- Angiography was evaluated by visual estimation, so there was chance of inter observer and intra observer variation of interpretation of the TIMI flow and MBG.

\section{Conclusion:}

The results of this study strongly support the prognosticimplication of time delay in patients with STEMI undergoing primary PCI. Therefore, all efforts should be made to shorten total ischemic time, including reduction in patient related delays, to improve clinical outcome of STEMI patients.

\section{References:}

1. Walker B R, Colledge N R, Ralston S H, Penman I. Davidson's Principle and Practice of Medicine. In: Newby D E, Grubb N R, eds. Cardiovascular disease. London:Churchil living stone Elsevier; 2014:579-581.

2. Granger CB, Kenneth WM, Douglas WW. Pexelizumab, an anti C5 complement antibody, as adjunctive therapy to primary percutaneous coronary intervention in acute myocardial infarction: the complement inhibition in myocardial infarction treated with angioplasty (COMMA) trail. Circulation 2006; 108: 1184-1190.

3. Elliott MA. Braunwald heart disease. In: ST elevation myocardial infarction: pathology, pathophysiology and clinical features. Missouri, USA: Elsevier Saunders, 2012;1087-1109.

4. Moscucci M, Eagle KA. Door-to-balloon time in primary percutaneous coronary intervention: is the 90 -minute gold standard an unreachable chimera? Circulation 2006; 113(8):1048-50.

5. Beohar N, Davidson CJ, Weigold G. Predictors of long-term outcomes following direct percutaneous coronary intervention for acute myocardial infarction. Am J Cardiol 2001; 88:1103-7

6. Geisler T, Muller K, Karathanos A. Impact of antithrombotic treatment on short term outcomes after PCI of left main disease: a pooled analysis from REPLACE 2, ACUITY, and HORIZONS-AMI trails. Euro intervention 2014; 10(1):97-104

7. Wilhelmsson C, Vedin JA, Elmfeldt D. Smoking and Myocardial Infarction. Lancet 1975; 1:415-420.

8. Jensen LO, Maeng M, Thayssen P. Influence of diabetes mellitus on clinical outcomes following primary percutaneous coronary intervention in patients with ST-segment elevation myocardial infarction. Am J Cardiol 2012; 109(5):629-35.

9. S. N. Willich, J. M “ uller-Nordhorn, M. Kulig. Cardiac risk factors, medication, and recurrent clinical events after acute coronary disease: a prospective cohort study. European Heart Journal 2001; 22(4):307-313.

10. P. S. Yusuf, S. Hawken, S. `Ounpuu.Eûect of potentially modiûable risk factors associated with myocardial infarction in 52 countries (the INTERHEART study): case-control study. Lancet 2004; 364 (9438);937-952.

11. De Luca G, Dirksen MT, Spaulding C. Impact of hypertension on clinical outcome in STEMI patients undergoing primary angioplasty with BMS or DES: insights from the DESERT cooperation. Int J Cardiol; 175:50-4.

12. Fang J, Alderman MH. Dissociation of hospitalization and mortality trends for myocardial infarction in the United States from 1988 to 1997. Am J Med 2002; 113:208.

13. Krikorian RK, Vacke JL, Beauchamp GD. Timing, mode, and predictors of death after direct angioplasty for acute myocardial infarction. CathCardiovascDiag 1995; 35:192-196.

14. Hermanides RS, Ottervanger JP, Dambrink JH. Incidence, predictors and prognostic importance of bleeding after primary PCI for STelevation myocardial infarction 2010; 6:106-11. 
15. Mehta RH, Harjai KJ, Grines L. Sustained ventricular tachycardia or fibrillation in the cardiac catheterization laboratory among patients receiving primary percutaneous coronary intervention: incidence, predictors, and outcomes. J Am CollCardiol 2014; 43:1765-1772.

16. Grines CL, Browne KF, Marco J. A comparison of immediate angioplasty with thrombolytic therapy for acute myocardial infarction. The primary angioplasty in myocardial infarction study group. N Eng J Med 1993; 328:673-9.
17. Fokkema, M. L., Wieringa W. G., Horst I.C.V.D., Boersma E., Zijlstra F., Smet B J. Outcome after percutaneous coronary intervention Groningen. Am J Cardiol. 2011;108:1536-1541 .

18. Falk E, Thuesen L. Pathology of coronary microembolisation and no reflow. Heart 2003;89:983-985.

19. Francone M, Bucciarelli-Ducci C, Carbone I, Canali E, Scardala R, Calabrese FA, et al. Impact of primary coronary angioplasty delay on myocardial salvage, infarct size, and microvascular damage in patients with ST-segment elevation myocardial infarction: insight from cardiovascular magnetic resonance. J Am CollCardiol 2009;54:2145-2153. 